\title{
$1.25 \mathrm{Cr}-0.5 \mathrm{Mo}$ 과 $2.25 \mathrm{Cr}-1 \mathrm{Mo}$ 강의 동적 변형시효 거동에 미치는 합금원소 및 미세조직의 영향 \\ 이요섭 ${ }^{1,2} \cdot$ 이호중 ${ }^{1} \cdot$ 이종현 ${ }^{2, *}$ \\ 1한국수력원자력(주) 중앙연구원 \\ 2충남대학교 신소재공학과
}

\section{Effect of Alloying Elements and Microstructure on the Dynamic Strain Aging Behavior of $1.25 \mathrm{Cr}-0.5 \mathrm{Mo}$ and $2.25 \mathrm{Cr}-1 \mathrm{Mo}$ Steels}

\author{
Yo Seob Lee ${ }^{1,2}$, Ho Jung Lee ${ }^{1}$, and Jong Hyeon Lee ${ }^{2, *}$ \\ ${ }^{1}$ Central Research Institute, Korea Hydro\&Nuclear Power, Daejeon 34101, Republic of Korea \\ ${ }^{2}$ Department of Materials Science and Engineering, Chungnam National University, Daejeon 34134, Republic of Korea
}

\begin{abstract}
The effect of alloying elements and microstructure on the dynamic strain aging (DSA) behavior of 1.25Cr-0.5Mo (P11, ASTM 335Gr.P11) and 2.25Cr-1Mo (P22, ASTM 335Gr.P22) steels was investigated. For both steels, different cooling conditions such as air-cooling (AC) and oil-quenching (OQ) were applied. Tensile tests were conducted in the temperature range of $20-450^{\circ} \mathrm{C}$ and a strain rate in the range of $6 \times 10^{-5}-6 \times 10^{-3} \mathrm{~s}^{-1}$ for the steels with different cooling conditions. The P11AC steel showed serration behavior over a wider temperature range and exhibited higher ultimate tensile strength (UTS) than for the P22AC steel. This is attributed to the effects of alloying elements $(\mathrm{Cr}, \mathrm{Mo}$ and $\mathrm{Si}$ ) due to dissolved $\mathrm{C}$, and the ferrite fraction on mechanical behavior. Meanwhile, the P11AC and P11OQ steels also showed different behaviors for DSA starting temperature, DSA temperature range, and serration type. The AC condition showed higher UTS from the interaction solid solution hardening (ISSH) effect due to substitutional $\mathrm{Cr}$, Mo, and interstitial C elements. The calculated activation energy value (Q) for the P11 steel was around $94-103 \mathrm{~kJ} / \mathrm{mol}^{-1}$, similar to that of ferritic steels, and it was higher for the P22 steel, with a $\mathrm{Q}$ value of $233 \mathrm{~kJ} / \mathrm{mol}^{-1}$ from the ISSH effect.
\end{abstract}

(Received July 21, 2021; Accepted August 23, 2021)

Keywords: dynamic strain aging, $1.25 \mathrm{Cr}-0.5 \mathrm{Mo}$ steel, $2.25 \mathrm{Cr}-1 \mathrm{Mo}$ steel, interaction solid solution hardening, heat treatment, carbides

\section{1. 서 론}

$1.25 \mathrm{Cr}-0.5 \mathrm{Mo}$ 과 $2.25 \mathrm{Cr}-1 \mathrm{Mo}$ 강은 $\mathrm{Mo}(0.5 \sim 1.0 \%)$ 와 $\mathrm{Cr}(1.0 \sim 2.25 \%)$ 를 함유하여 고온 강도 및 부식 저항성이 우수한 재료로써, 화력 및 원자력 발전소의 압력용기, 고온 튜브, 증기배관 등 발전소의 고온 재료로 널리 사용되고 있다. $1.25 \mathrm{Cr}-0.5 \mathrm{Mo}$ 강은 웨스팅하우스가 개발한 $\mathrm{AP} 1000$ 원전의 주증기배관 재료로 설계에 반영 [1]되어 있고 두 재료 모두 국내외 원전의 주증기배관과 주급수배관으로 사

- 이요섭: 박사과정 선임전문원, 이호중: 선임연구원, 이종현: 교수 *Corresponding Author: Jong Hyeon Lee [Tel: +82-42-821-6596, E-mail: jonglee@cnu.ac.kr] Copyright (C) The Korean Institute of Metals and Materials
용되고 있으며 수출형원전의 주증기배관 후보 재료로 검토 되고 있다.

원전의 고에너지 배관인 주증기배관에 파단전누설 (Leak before break) 개념을 적용하면 배관의 양단파단 (Double ended guillotine break) 가정을 설계에서 배제할 수 있다. 이로 인해 양단파단으로 인한 동적 영향의 확산을 방지하 기 위하여 설치하는 배관 구속 장치와 분출 방지벽을 제거 하고, 동적 하중을 설계에서 배제하여 설계 하중을 줄일 수 있는 이점이 있다. 이러한 파단전누설 개념의 적용을 위해서는 파단전누설 설계여유도의 주요 변수인 동적 변형 시효 (Dynamic strain aging)의 영향 평가가 필수적이다. $\mathrm{Cr}-\mathrm{Mo}$ 강의 동적 변형시효 거동 [2-10]에 대해 많은 연 구가 수행되어 동적 변형시효가 특정 온도 구간에서 소성 
Table 1. Chemical composition of SA355 Gr. P11 (P11) and SA355 Gr. P22 (P22) used in this study in wt. \%.

\begin{tabular}{ccccccccccc}
\hline & Material & $\mathrm{Fe}$ & $\mathrm{C}$ & $\mathrm{Cr}$ & $\mathrm{Mo}$ & $\mathrm{Si}$ & $\mathrm{Mn}$ & $\mathrm{P}$ & $\mathrm{S}$ \\
\hline \multirow{2}{*}{ P11 } & ASME spec. & Bal. & $<0.15$ & $1.0-1.5$ & $0.44-0.65$ & $0.5 \sim 1.0$ & $0.3-0.6$ & $<0.025$ & $<0.025$ \\
& CMTR & Bal. & 0.14 & 1.1 & 0.47 & 0.57 & 0.45 & 0.006 & 0.004 \\
\hline \multirow{2}{*}{ P22 } & ASME spec. & Bal. & $<0.15$ & $1.9-2.6$ & $0.87-1.13$ & $<0.5$ & $0.3 \sim 0.6$ & $<0.025$ & $<0.025$ \\
& CMTR & Bal. & 0.14 & 2.1 & 0.93 & 0.25 & 0.43 & 0.010 & 0.003 \\
\hline
\end{tabular}

변형 동안 이동 전위와 확산 원자의 상호작용에 의해 발생 하는 것으로 파악되었으나, 합금원소 및 미세조직의 영향 에 대한 연구보고는 미흡한 실정이다.

본 연구에서는 주증기배관 후보 재료 $1.25 \mathrm{Cr}-0.5 \mathrm{Mo}$ 과 $2.25 \mathrm{Cr}-1 \mathrm{Mo}$ 강에 대해 냉각속도를 다르게 열처리를 수행한 시편으로 다양한 온도 및 변형률 속도 구간에서 인장특성 평가 및 미세조직 분석을 수행하여 합금원소 및 미세조직 차이가 동적 변형시효 특성에 미치는 영향을 평가하였다.

\section{2. 실험 방법}

\section{1 재료 및 열처리 조건}

본 실험에서는 $1.25 \mathrm{Cr}-0.5 \mathrm{Mo}$ 강 (P11, $\mathrm{ASME} \mathrm{SA335}$ Gr.P11)과 2.25Cr-1Mo강 (P22, ASME SA335 Gr.P22) 을 사용하였고 두 재료의 화학 조성을 표 1에 나타내었 다. 재료의 열처리 조건으로 $920{ }^{\circ} \mathrm{C}$ 에서 5 분 노말라이징 (normalizing) 후 공냉 (AC, air cooling)을 하고 $720^{\circ} \mathrm{C}$ 에 서 30분 템퍼링 (tempering) 후 공냉을 하였다. 또한 미세조 직의 영향을 분석하기 위한 다른 열처리 조건으로 두 재료 모두 $930{ }^{\circ} \mathrm{C}$ 에서 노말라이징 후 오일냉각 $(\mathrm{OQ}$, oil quenching)을 하고 $720^{\circ} \mathrm{C}$ 에서 1시간 템퍼링 후 공냉을 하 였다. 두재료의 공냉 시편을 $\mathrm{P} 11 \mathrm{AC}, \mathrm{P} 22 \mathrm{AC}$, 오일냉각 시 편을 P11OQ, P22OQ로 명명하였다.

4종 소재를 각각 마운팅 후 연마한 시편을 $2 \%$ 나이탈 용 액으로 에칭을 하고 광학현미경 (OM, optical microscope) 으로 거시적 미세조직을 분석 하였고 광학현미경의 이미지 분석기(TOMORO analySIS TS)를 통해 peralite/ferrite 상분 율을 분석하였다. 이후 주사전자현미경 (SEM, scanning electron microscope)과 투과전자현미경 (TEM, transmission electron microscope)을 이용하여 상세 미세조직과 석출물 분 포와 종류를 분석하였다. 투과전자현미경 분석용 시편은 집 속이온빔 (FIB, focused ion beam)를 이용하여 $5 \times 6 \mu \mathrm{m}$ (가로 $\times$ 세로) 및 $100 \mathrm{~nm}$ (두께) 이하의 샘플을 만들었으며 EDS (energy dispersive spectroscope) 원소 mapping을 통해 석출물의 화학 조성을 파악하고 HRTEM (high resolution TEM) 모드에서 FFT (fast fourier transform)
를 통해 석출물의 종류를 분석하였다.

\section{2 인장시험}

인장 시편은 4종 소재 블록의 내호에서 길이 방향으로 채취하였고 ASTM E8 방법에 따라 평형부의 직경과 길이 가 각각 $5 \mathrm{~mm}$ 와 $32 \mathrm{~mm}$ 인 봉상으로 가공하였다. 인장시 험은 유압식 만능재료시험기 (Instron 8801)를 사용하여 변 형률 속도 $6 \times 10^{-3} \sim 6 \times 10^{-5} \mathrm{~s}^{-1}$ 으로 $20 \sim 450^{\circ} \mathrm{C}$ 의 온도범위 에서 수행하였다. 응력-변형률 곡선으로부터 $0.2 \%$ off-set 유동응력을 항복강도 (YS, yield strength)로 정하고, 최대 인장강도 (UTS, ultimate tensile strength), 파단 연신율 (TE, total elongation)을 측정하였다.

\section{3. 결과 및 고찰}

\section{1 열처리에 따른 미세조직}

4종 소재의 미세조직을 광학현미경으로 관찰하여 그림 1 에 나타내었다. 그림 1(a), (b)의 공냉을 수행한 P11AC와 $\mathrm{P} 22 \mathrm{AC}$ 에서는 모두 ferrite-pearlite 조직이 관찰되었다. Peralite/ferrite 상분율 분석결과, $\mathrm{P} 22 \mathrm{AC}$ 의 pearlite 함량이 $14.7 \%$ 로 $8.2 \%$ 인 $\mathrm{P} 11 \mathrm{AC}$ 보다 많아 $\mathrm{Cr}$ 과 $\mathrm{Mo}$ 함량이 많

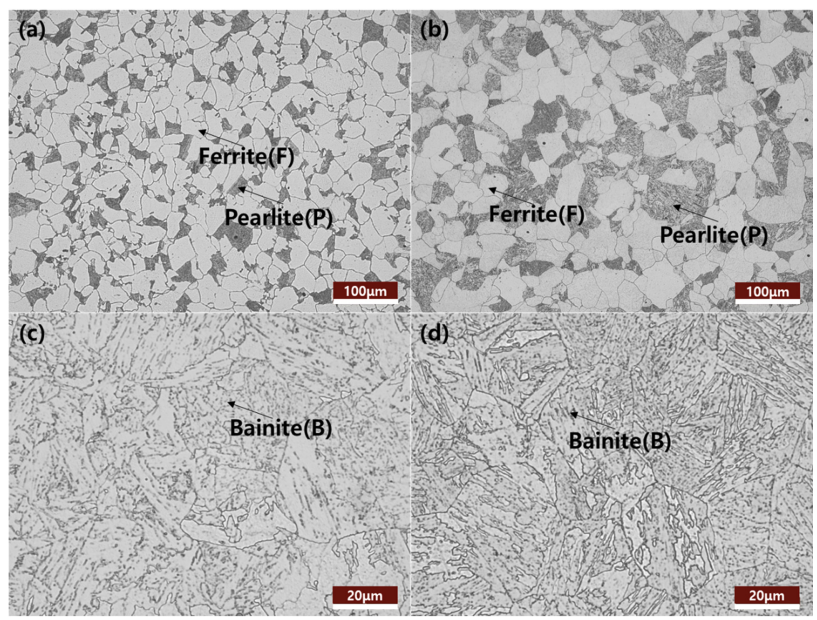

Fig. 1. OM images of (a) P11AC (ferrite-pearlite), (b) P22AC (ferrite-pearlite), (c) P11OQ (bainite), and (d) P22OQ (bainite) specimens. 




Fig. 2. SEM images of (a) P11AC, (b) P22AC, (c) P11OQ, and (d) P22OQ specimens.

은 $\mathrm{P} 22 \mathrm{AC}$ 에서 $\mathrm{P} 11 \mathrm{AC}$ 보다 상대적으로 더 많은 pearlite 조직이 관찰되었음을 알 수 있다. 반면 그림 $1(\mathrm{c}),(\mathrm{d})$ 의 오일 냉각을 수행한 $\mathrm{P} 11 \mathrm{OQ}$ 와 $\mathrm{P} 22 \mathrm{OQ}$ 에서는 모두 bainite 조직이 관찰되었다.

주사전자현미경으로 석출물 크기 및 분포를 관찰하여 그 림 2에 나타내었다. 그림 2(a)의 P11AC에서는 석출물이 ferrite 결정 (grain) 내부의 일부를 제외하고는 대부분 결정 입계 (grain boundary)에 분포되어 있지만 $\mathrm{Cr}, \mathrm{Mo}$ 함량이 많은 그림 2(b)의 P22AC에서는 석출물이 결정입계와 결정 내부에도 미세하게 전반적으로 형성되어 있다. 그림 2(c), (d)의 $\mathrm{P} 11 \mathrm{OQ}$ 와 $\mathrm{P} 22 \mathrm{OQ}$ 에서는 bainite 조직이 관찰되었다. 투과전자현미경으로 석출상을 상세하게 관찰한 결과를 그림 3에 나타내었다. ferrite 내부 및 결정립계에 관찰되는 석출물은 그림 $3(\mathrm{a}),(\mathrm{b})$ 의 $\mathrm{P} 11 \mathrm{AC}$ 와 $\mathrm{P} 22 \mathrm{AC}$ 와 같이 $\mathrm{M}_{2} \mathrm{C}, \mathrm{M}_{3} \mathrm{C}$ 로 분석되었고 주사전자현미경 관찰에서와 같이 $\mathrm{Cr}, \mathrm{Mo}$ 함량이 많은 $\mathrm{P} 22 \mathrm{AC}$ 의 석출상이 $\mathrm{P} 11 \mathrm{AC}$ 보다 크 고 많이 분포되어 있는 것을 알 수 있다. 반면 bainite 조 직의 그림 $3(\mathrm{c}),(\mathrm{d})$ 의 $\mathrm{P} 11 \mathrm{OQ}$ 에서는 $\mathrm{Cr}$ 이 주성분인 $\mathrm{M}_{3} \mathrm{C}$ 가 관찰되었고 $\mathrm{P} 22 \mathrm{OQ}$ 에서는 $\mathrm{Mo}$ 가 주성분인 $\mathrm{M}_{2} \mathrm{C}$ 가 형성 되어 있는 것으로 분석되었다.

\section{2 인장 시험 및 동적 변형시효 거동}

동적 변형시효 현상은 용질 원자의 확산을 지배하는 온 도와 전위의 이동을 결정하는 변형률 속도가 밀접한 관계 를 가진다. Rodriguez 등 $[11,12]$ 에 의하면 동적변형시효 거동은 다음과 같은 특성을 보인다. 첫째는 응력-변형률 곡 선에서 관찰되는 serration 현상이고, 둘째는 온도에 따른 기계적 특성 변화로 특정 온도 구간에서 최대인장강도의 최고점 (peak) 현상, 항복 강도의 평탄화 (plateau), 온도에 따른 연신율의 최저 온도 구간 발생이다. 셋째는 변형률 속도 민감도 (strain rate sensitivity)가 음이 되는 온도 구 간이 발생하는 것이다. 또한, 활성화에너지 계산을 통해 동 적변형시효 발생 거동의 특성을 파악할 수 있다.

Serration 발생 특성을 확인하기 위해 변형률 구간을


Fig. 3. TEM images of the (a) P11AC, (b) P22AC, (c) P11OQ, and (d) P22OQ specimens. 



Fig. 4. Stress-strain curves of (a) P11AC, (b) P22AC, (c) P11OQ, and (d) P22OQ at test temperatures and strain rate of $6 \times 10^{-4} \mathrm{~s}^{-1}$.

Table 2. Serration status of (a) P11AC, (b) P22AC, (c) P11OQ, and (d) P22OQ at test temperatures and strain rate of $6 \times 10^{-4}$. $\circ:$ Serration, $\times$ : No serration, -: No test

\begin{tabular}{cccccccccc}
\hline Specimen & $20{ }^{\circ} \mathrm{C}$ & $100{ }^{\circ} \mathrm{C}$ & $150{ }^{\circ} \mathrm{C}$ & $200{ }^{\circ} \mathrm{C}$ & $250{ }^{\circ} \mathrm{C}$ & $286{ }^{\circ} \mathrm{C}$ & $316{ }^{\circ} \mathrm{C}$ & $350{ }^{\circ} \mathrm{C}$ & $450{ }^{\circ} \mathrm{C}$ \\
\hline P11AC & $\times$ & $\times$ & $\bigcirc$ & $\bigcirc$ & $\bigcirc$ & $\bigcirc$ & $\times$ & $\times$ & $\times$ \\
P22AC & $\times$ & - & - & $\times$ & $\times$ & $\bigcirc$ & $\bigcirc$ & $\times$ & $\times$ \\
P11OQ & $\times$ & $\times$ & $\bigcirc$ & $\bigcirc$ & $\bigcirc$ & $\times$ & $\times$ & $\times$ & $\times$ \\
P22OQ & $\times$ & - & - & $\times$ & $\bigcirc$ & $\bigcirc$ & $\bigcirc$ & $\times$ & $\times$ \\
\hline
\end{tabular}

$2.5 \%$ 씩 이동하여 변형률 속도 $6 \times 10^{-4} \mathrm{~s}^{-1}$ 에서 인장시험을 수행한 응력-변형률 곡선을 그림 4에 나타내었다. 각 재료 의 serration 발생 현황을 정리한 표 2에서 ferrite-pearlite 조직의 serration 발생 차이를 확인한 결과, $\mathrm{P} 11 \mathrm{AC}$ 에서는 $150 \sim 286{ }^{\circ} \mathrm{C}, \mathrm{P} 22 \mathrm{AC}$ 에서는 $286 \sim 316^{\circ} \mathrm{C}$ 에서 serration이 관 찰되어 P11AC의 serration 발생 온도 범위가 P22AC 보다 넓었으며 저온에서 발생하였다. Bainite 조직의 P11OQ에서 는 $150 \sim 250{ }^{\circ} \mathrm{C}, \mathrm{P} 22 \mathrm{OQ}$ 에서는 $250 \sim 316^{\circ} \mathrm{C}$ 에서 serration이 관찰되어 bainite 조직에서도 $\mathrm{P} 11 \mathrm{OQ}$ 의 serration 온도 범위 가 $\mathrm{P} 22 \mathrm{OQ}$ 보다 넓었으며 상대적으로 저온에서 발생하였다.

변형률 속도 $6 \times 10^{-3} \sim 6 \times 10^{-5} \mathrm{~s}^{-1}$ 으로 $20 \sim 450^{\circ} \mathrm{C}$ 의 범위 에서 인장시험을 수행하여 최대인장강도, 항복강도 및 파 단연신율의 변화를 그림 5,6 에 나타내었다. 그림 5(a), 6(a)에서 시험온도 증가에 따라 감소하던 최대인장강도가 $300{ }^{\circ} \mathrm{C}$ 근처에서 증가하다가 다시 감소하는 경향을 보였다.
동적 변형시효의 일반적인 특징과 같이 변형률 속도가 느 릴수록 최대인장강도의 최고점이 컸으며 변형률 속도가 빠 를수록 최고점이 고온에서 관찰되었다. 그림 5(b), 6(b)에 서 항복강도는 평탄화 구간을 형성한 후 감소하는 것으로 나타났으며, 두 조직 모두 P22에서 평탄화 구간이 좀 더 뚜렷하게 나타났다. 그림 5(c), 6(c)에서 파단연신율이 동적 변형시효 온도 구간에서 감소하였다가 이후 증가하는 경향 을 보였는데 두 조직 모두 $\mathrm{P} 22$ 에서 연신율의값이 작게 나 타났다. 최대인장강도, 항복강도 및 파단연신율의 변화를 통해 4종 시편에서 동적 변형시효 현상이 발생하는 것을 확인할 수 있었다.

변형률 속도 $6 \times 10^{-4} \mathrm{~s}^{-1}$ 로 $20 \sim 450{ }^{\circ} \mathrm{C}$ 의 범위에서 인장 시험을 수행하여 최대인장강도, 항복 강도 및 파단연신율 의 측정 결과를 그림 7과 표 3에 나타내었다.

그림 7의 최대인장강도는 공냉으로부터 얻어진 ferrite- 



Fig. 5. Variation of (a) UTS, (b) YS, and (c) TE of P11 at test temperatures and strain rates.

pearlite 조직과 오일냉각에서얻어진 bainite 조직 모두 상온 에서 온도가 증가할수록 감소하다가 일정온도 범위에서 증 가하였다. ferrite-pearlite 조직의 경우 $150{ }^{\circ} \mathrm{C}$ 부터 증가하
Fig. 6. Variation of (a) UTS, (b) YS, and (c) TE of P22 at test temperatures and strain rates.

다가 $200 \sim 450{ }^{\circ} \mathrm{C}$ 의 범위에서 $\mathrm{P} 11 \mathrm{AC}$ 의 최대인장강도가 $\mathrm{P} 22 \mathrm{AC}$ 보다 크게 나타났다. Bainite 조직에서도 286 $350{ }^{\circ} \mathrm{C}$ 에서 $\mathrm{P} 11 \mathrm{OQ}$ 의 최대인장강도가 $\mathrm{P} 22 \mathrm{OQ}$ 보다 크게 

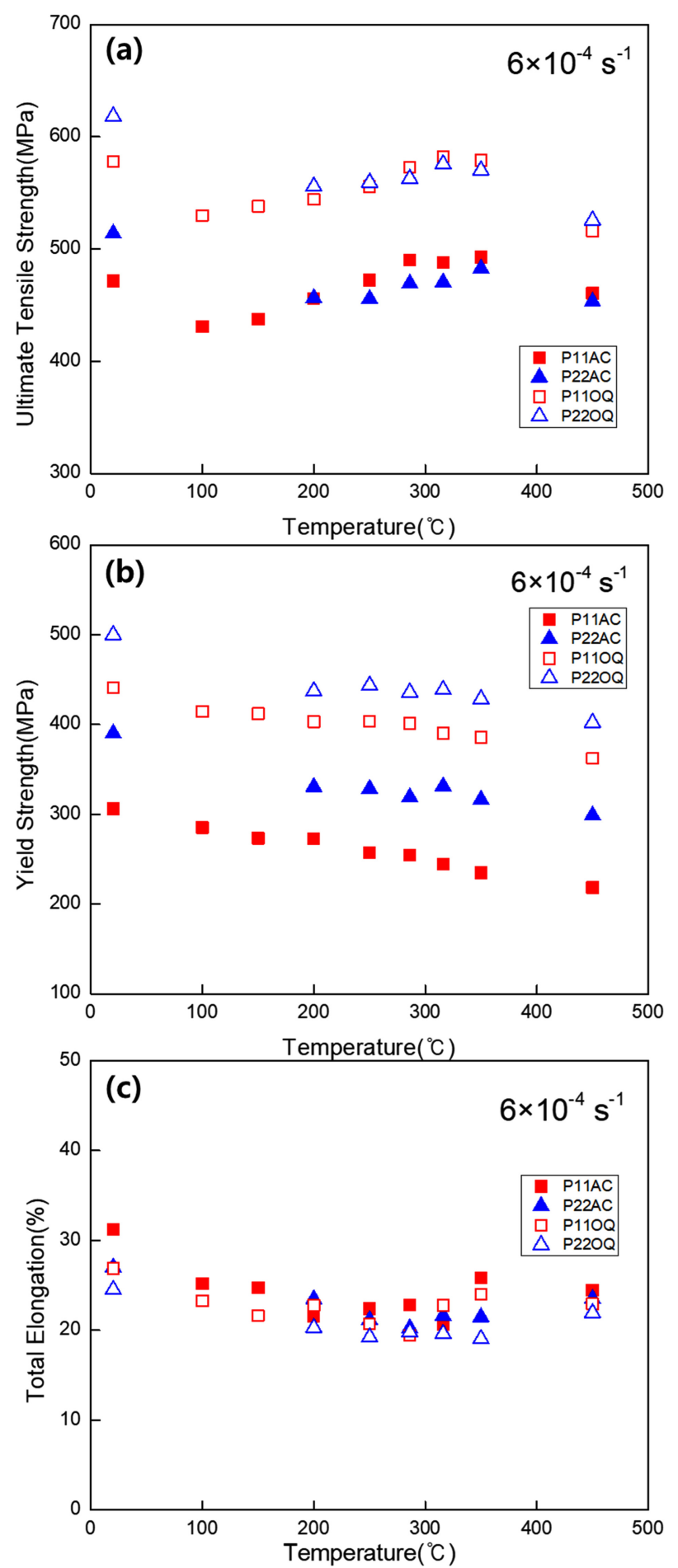

Fig. 7. Variation of (a) UTS, (b) YS, and (c) TE of P11AC vs $\mathrm{P} 22 \mathrm{AC}$ and $\mathrm{P} 11 \mathrm{OQ}$ vs $\mathrm{P} 22 \mathrm{OQ}$ at test temperatures and strain rate of $6 \times 10^{-4} \mathrm{~s}^{-1}$.

나타났다.

주증기배관 온도 $\left(286{ }^{\circ} \mathrm{C}\right)$ 에서 변형률 속도 별 최대인장
Table 3. Tensile properties of (a) P11AC, (b) P22AC, (c) P11OQ, and (d) P22OQ at test temperatures and strain rate of $6 \times 10^{-4}$.

\begin{tabular}{|c|c|c|c|c|}
\hline \multirow{2}{*}{ Specimen } & \multirow{2}{*}{$\begin{array}{c}\text { Temp. } \\
\left({ }^{\circ} \mathrm{C}\right)\end{array}$} & \multicolumn{2}{|c|}{ Strength (MPa) } & \multirow{2}{*}{$\begin{array}{c}\text { Total Elongation } \\
(\%)\end{array}$} \\
\hline & & Yield & Tensile & \\
\hline \multirow{9}{*}{ P11AC } & 20 & 306.04 & 471.41 & 31.22 \\
\hline & 100 & 285.22 & 431.05 & 25.17 \\
\hline & 150 & 273.38 & 437.49 & 24.75 \\
\hline & 200 & 272.74 & 455.64 & 21.55 \\
\hline & 250 & 257.22 & 472.16 & 22.40 \\
\hline & 286 & 254.48 & 490.07 & 22.79 \\
\hline & 316 & 244.19 & 487.91 & 20.63 \\
\hline & 350 & 234.68 & 492.71 & 25.81 \\
\hline & 450 & 218.35 & 460.53 & 24.46 \\
\hline \multirow{7}{*}{$\mathrm{P} 22 \mathrm{AC}$} & 20 & 390.07 & 513.81 & 27.01 \\
\hline & 200 & 330.60 & 456.19 & 23.47 \\
\hline & 250 & 328.48 & 455.54 & 21.15 \\
\hline & 286 & 319.04 & 469.29 & 20.24 \\
\hline & 316 & 331.21 & 470.28 & 21.61 \\
\hline & 350 & 316.36 & 482.72 & 21.47 \\
\hline & 450 & 298.79 & 453.20 & 23.51 \\
\hline \multirow{9}{*}{ P11OQ } & 20 & 440.89 & 577.96 & 26.88 \\
\hline & 100 & 414.63 & 529.82 & 23.28 \\
\hline & 150 & 412.02 & 538.05 & 21.62 \\
\hline & 200 & 403.22 & 544.10 & 22.79 \\
\hline & 250 & 403.68 & 555.65 & 20.71 \\
\hline & 286 & 401.19 & 572.69 & 19.42 \\
\hline & 316 & 390.38 & 582.47 & 22.77 \\
\hline & 350 & 385.55 & 579.10 & 24.01 \\
\hline & 450 & 362.48 & 515.97 & 22.95 \\
\hline \multirow{7}{*}{ P22OQ } & 20 & 500.00 & 618.22 & 24.51 \\
\hline & 200 & 437.20 & 555.71 & 20.26 \\
\hline & 250 & 443.67 & 559.22 & 19.22 \\
\hline & 286 & 435.89 & 562.61 & 19.77 \\
\hline & 316 & 438.80 & 575.83 & 19.62 \\
\hline & 350 & 428.32 & 570.08 & 19.03 \\
\hline & 450 & 401.96 & 525.58 & 21.91 \\
\hline
\end{tabular}

강도를 그림 8 에 나타내었다. 변형률 속도의 증가에 따라 최대인장강도가 감소하는 경향을 보여 $286{ }^{\circ} \mathrm{C}$ 에서 동적 변 형시효가 발생함을 알 수 있다. 또한, 다음의 관계식 $[13,14]$ 으로 진변형률 0.05 에서의 응력으로 변형률 속도 민감도 $(\mathrm{m})$ 를 계산하고 그림 9에 나타내었다.

$$
m=\partial \ln \sigma / \partial \ln \dot{\varepsilon}=\log \left(\sigma_{1} / \sigma_{2}\right) / \log \left(\dot{\varepsilon}_{1} / \dot{\varepsilon}_{2}\right)
$$

여기서, $\dot{\varepsilon}_{1}: 6 \times 10^{-4} \mathrm{~s}^{-1}, \dot{\varepsilon}_{2}: 6 \times 10^{-5} \mathrm{~s}^{-1}, \sigma_{1}: \dot{\varepsilon}_{1}$ stress, $\sigma_{2}: \dot{\varepsilon_{2}}$ stress 그림 9에서 변형률 속도 민감도 $(\mathrm{m})$ 가 동적 변형시효 발 생 온도구간에서 음의 값이 나타나므로 모든 시편에서 동 적 변형시효 현상을 확인할 수 있었으나 합금조성과 미세 조직에 따른 차이는 발견되지 않았다. 


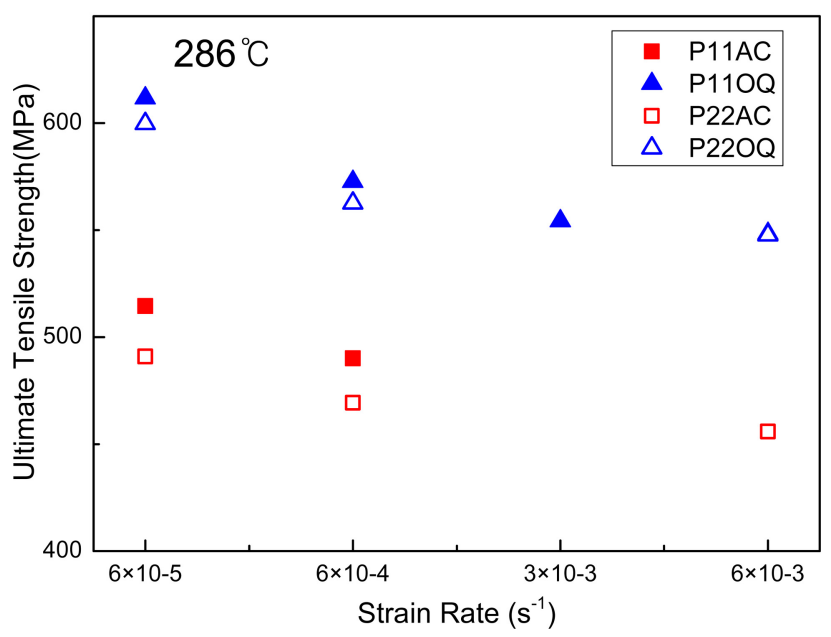

Fig. 8. Strain rate dependence of the ultimate tensile strength for all alloys tested at $286^{\circ} \mathrm{C}$.

동적 변형시효 현상은 확산하는 용질 원자와 이동 전위 의 상호작용에 의해 발생하는 열적 활성화 과정이므로, 활 성화에너지 계산을 통해 동적 변형시효 발생 거동의 차이 를 분석하였다. 시험 온도와 변형률 속도에서 serration 발 생 여부를 그림 10에 나타내었고 serration이 발생하는 열

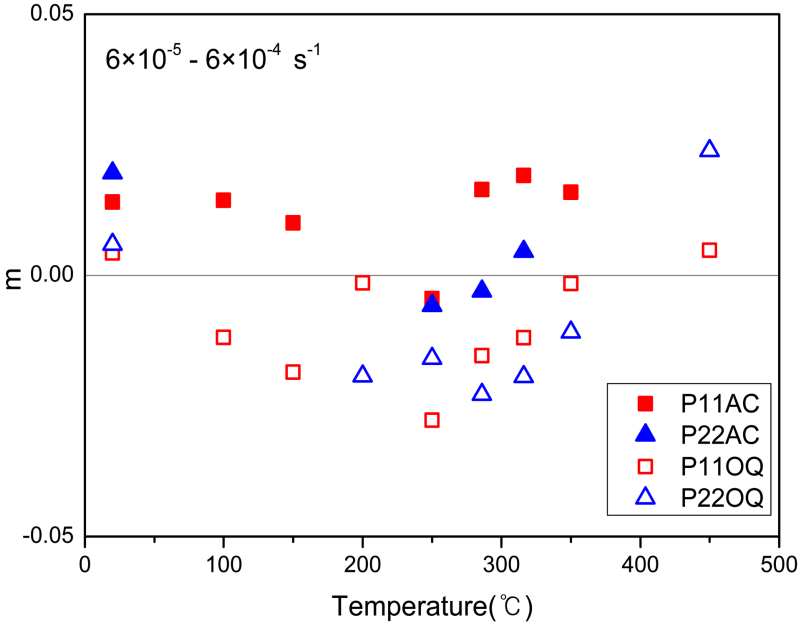

Fig. 9. Effect of test temperatures on strain rates sensitivity (SRS) for all alloys between strain rate of $6 \times 10^{-5} \mathrm{~s}^{-1}$ and $6 \times 10^{-4} \mathrm{~s}^{-1}$.

적 활성화 에너지 $(\mathrm{Q})$ 를 다음의 Arrhenius 식으로 계산하였 다 [15].

$d \varepsilon / d t=A \exp (-Q / R T)$
Ferrite-Pearlite of $1.25 \mathrm{Cr}-0.5 \mathrm{Mo}$

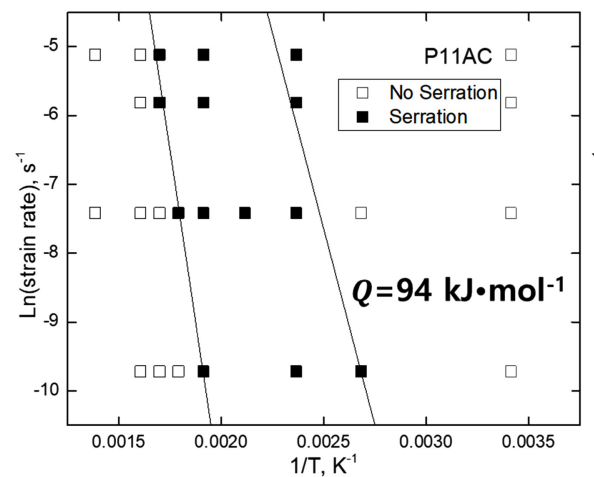

Bainite of $1.25 \mathrm{Cr}-0.5 \mathrm{Mo}$

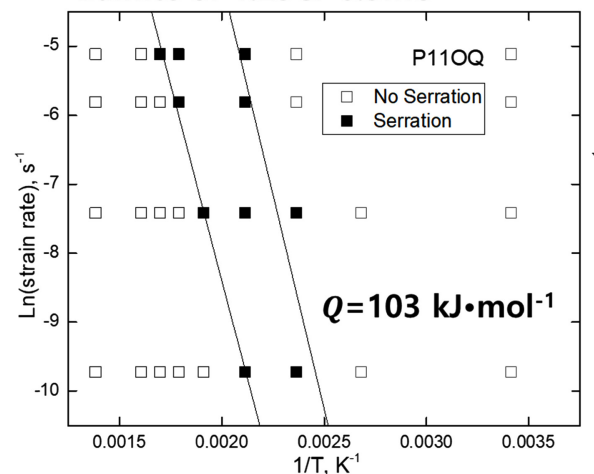

Ferrite-Pearlite of $2.25 \mathrm{Cr}-1 \mathrm{Mo}$



Bainite of $2.25 \mathrm{Cr}-1 \mathrm{Mo}$



Fig. 10. Serrated flow occurrence map obtained during tensile test with test temperatures and strain rates in the (a) P11AC, (b) P22AC, (c) P11OQ, and (d) P22OQ specimens. 
여기서, $\mathrm{R}$ : 기체상수 $(8.314 \mathrm{~J} / \mathrm{mol} / \mathrm{K}), \mathrm{T}$ : 온도 $(\mathrm{K}), \mathrm{Q}$ : 활성화에너지 $(\mathrm{kJ} / \mathrm{mol})$

$\mathrm{P} 11 \mathrm{AC}$ 의 활성화에너지 값은 $94 \mathrm{~kJ} / \mathrm{mol}$ 이고 $\mathrm{P} 22 \mathrm{AC}$ 는 $233 \mathrm{~kJ} / \mathrm{mol}, \mathrm{P} 11 \mathrm{OQ}$ 는 $103 \mathrm{~kJ} / \mathrm{mol}, \mathrm{P} 22 \mathrm{OQ}$ 는 $233 \mathrm{~kJ} / \mathrm{mol}$ 로 계산되었다. P11의 활성화에너지 값은 Choudhary [7] 의 연구결과인 $9 \mathrm{Cr}-1 \mathrm{Mo}$ ferritic 강의 활성화에너지 값 $(83 \mathrm{~kJ} / \mathrm{mol})$ 과 유사하였으나 $\mathrm{P} 22$ 의 활성화에너지 값은 크 게 계산되었다.

\section{3 합금조성 및 미세조직의 영향}

$\mathrm{P} 11 \mathrm{AC}$ 와 $\mathrm{P} 22 \mathrm{AC}$ 의 ferrite-pearlite 조직에서 합금조성 차이에 따른 serration 의 거동에 차이를 보였다. $\mathrm{Cr}$ 과 $\mathrm{Mo}$ 와 같은 치환형 원소가 용질 끌림 효과(Solute drag effect)에 의해 austenite와 ferrite 계면에 편석되고 $\mathrm{C}$ 의 확 산을 방해하여 ferrite의 생성 및 성장을 억제 시켜 $\mathrm{Cr}$, $\mathrm{Mo}$ 함량이 많은 $\mathrm{P} 22 \mathrm{AC}$ 에서 ferrite가 적었다. 반면 $\mathrm{Si}$ 는 Ollilainen 등 [16]의 연구결과와 같이 C 원자의 확산을 활성화시켜 ferrite의 생성 및 성장을 촉진하게 하여 $\mathrm{P} 11 \mathrm{AC}$ 에 더 많은 ferrite 형성에 영향을 끼쳤을 것으로 보 인다. $\mathrm{Cr}, \mathrm{Mo}$ 함량이 많은 $\mathrm{P} 22 \mathrm{AC}$ 는 그림 2(b)에서 볼 수 있듯이 ferrite내에 미세한 석출물 $\left(\mathrm{M}_{2} \mathrm{C}\right)$ 이 P11AC 보
다 더 많이 관찰되어 $\mathrm{P} 22 \mathrm{AC}$ 의 ferrite내 용존 $\mathrm{C}$ 의 함량이 적을 것으로 생각된다. 따라서 ferrite와 용존 $\mathrm{C}$ 가 더 많은 $\mathrm{P} 11 \mathrm{AC}$ 에서 저온부터 전위와 상호 작용을 시작하여 넓은 온도 범위에서 serration 현상이 나타난 것으로 생각된다. 위의 ferrite가 많은 P11AC에서 serration이 활발하게 발생 하는 현상은 선행 연구 결과들과 일치한다 [17-19]. 반면에 $\mathrm{P} 22 \mathrm{AC}$ 에서는 serration이 고온에서 관찰되었다. $2.25 \mathrm{Cr}-$ $1 \mathrm{Mo}$ 의 동적 변형시효 거동이 $100 \sim 300{ }^{\circ} \mathrm{C}$ 에서는 침입형원 소 $(\mathrm{C}, \mathrm{N})$ 와 전위의 상호작용에 의해 발생하고 고온에서는 고용된 침입형원소와 치환형원소 $(\mathrm{Cr}, \mathrm{Mo})$ 에 의해 발생한다 는 연구결과 $[4,20]$ 와 같이 용존 $\mathrm{C}$ 가 적은 $\mathrm{P} 22 \mathrm{AC}$ 는 저온 에서 serration이 발생하지 않고 치환형원소에 의해 고온에 서 발생한 것으로 판단된다.

$\mathrm{P} 11 \mathrm{AC}$ 와 $\mathrm{P} 11 \mathrm{OQ}$ 의 미세조직별 serration 거동을 확인하 기 위해 변형률 속도와 온도 별 serration type을 그림 11 에 나타내었다. Rodriguez [11]는 응력-변형률 곡선의 형상 으로 serration type을 정의하였으며, 선행 연구들에서 $\mathrm{A}$, $\mathrm{B}, \mathrm{C}$ type을 주로 분석에 활용하였다 [26-30]. Type A serration은 저온에서 침입형원소에 의한 전위의 고착 및 풀 림으로 진폭이 부드럽게 나타나고 type B serration은 전위 의 고착과 풀림이 빠르게 발생하여 진폭이 빠르게 나타나
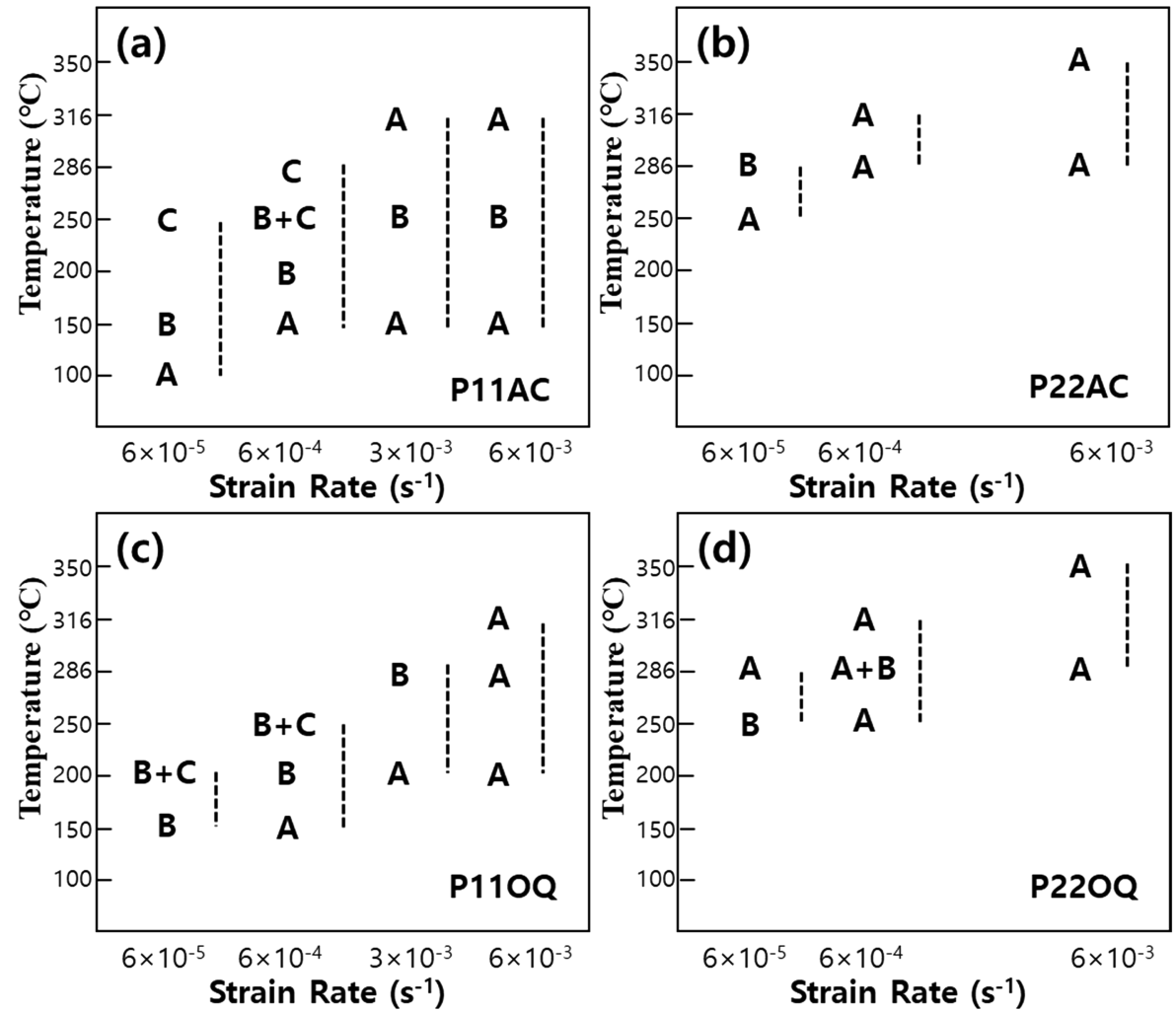

Fig. 11. Serrated flow type map obtained during tensile test with test temperatures and strain rates in the (a) P11AC, (b) P11OQ, (c) P22AC, and (d) P22OQ specimens. 
며, type C serration은 전위가 풀릴 때 발생하여 큰 진폭 을 보이며 고온에서 발생한다고 알려져 있다. 본 논문에서 는 응력-변형률 곡선의 형상으로 변형률 속도 $6 \times 10^{-4} \mathrm{~s}^{-1}$ 에서 재료들의 serration 형상을 분석하여 그림 12 에 나타 내었다.

Type A, B serration은 침입형원소에 의해 저온에서 발
생하고 type C serration은 치환형원소에 의해 고온에서 발생하는 것으로 알려져 있다 [21]. P11AC도 느린 변형률 속도의 저온에서는 type A serration이 관찰되었고 고온에 서는 type C serration이 관찰되어 느린 변형률 속도에서 는 선행 연구결과와 잘 일치하였다. 변형률 속도가 빨라지 면서 고온에서도 type A 또는 B serration이 관찰되어 빠

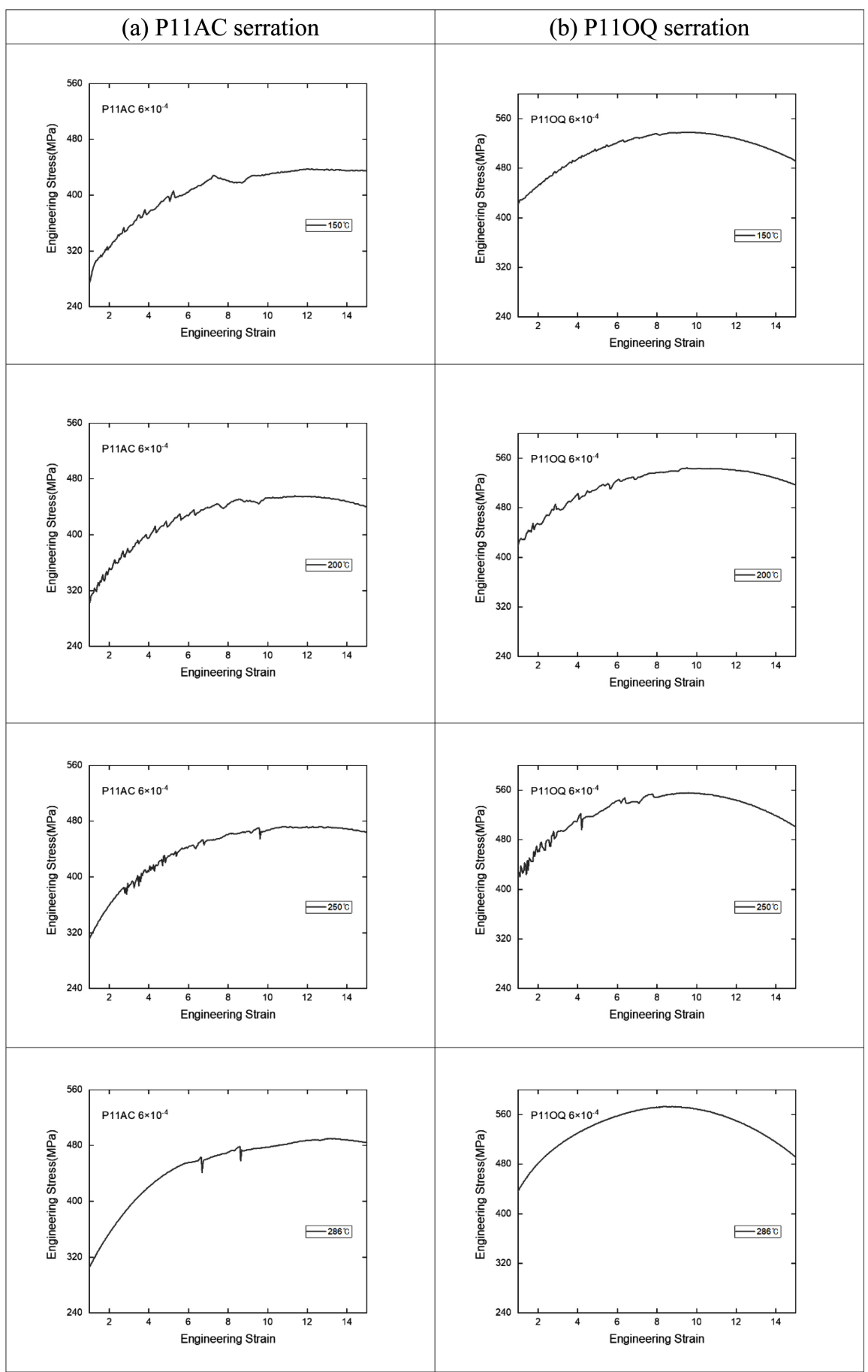

Fig. 12. Stress-strain curves of (a) P11AC, (b) P22AC, (c) P11OQ, and (d) $\mathrm{P} 22 \mathrm{OQ}$ at DSA temperatures and strain rate of $6 \times 10^{-4} \mathrm{~S}^{-1}$ 


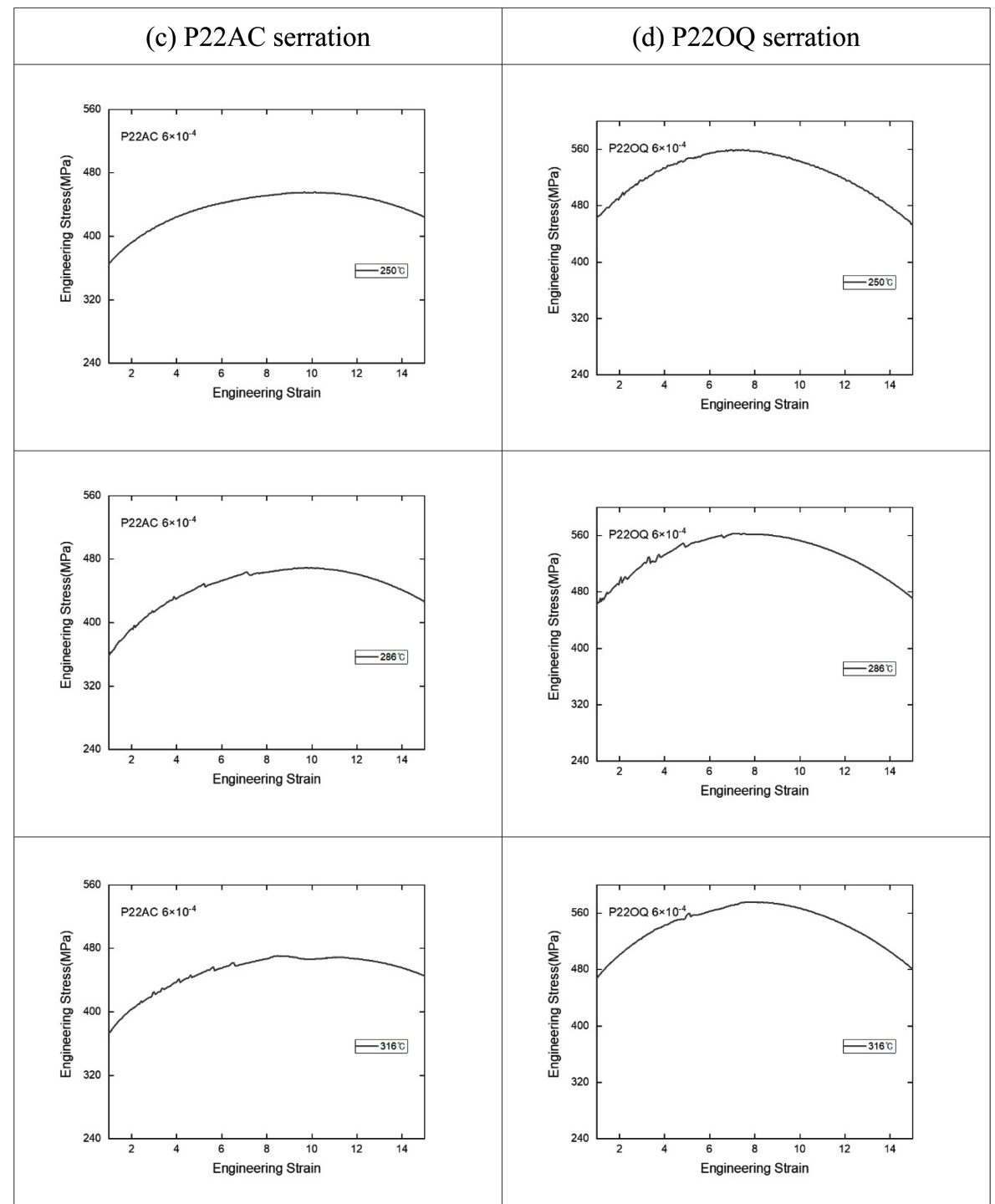

Fig. 12. Stress-strain curves of (a) $\mathrm{P} 11 \mathrm{AC}$, (b) $\mathrm{P} 22 \mathrm{AC}$, (c) $\mathrm{P} 11 \mathrm{OQ}$, and (d) $\mathrm{P} 22 \mathrm{OQ}$ at DSA temperatures and strain rate of $6 \times 10^{-4} \mathrm{~S}^{-1}$ (Continued)

른 변형률 속도에서는 온도와 관계없이 serration이 발생하 는 것으로 보인다. $\mathrm{P} 11 \mathrm{OQ}$ 는 느린 변형률 속도의 고온에서 type C serration이 일부 관찰되고 빠른 변형률 속도에서는 type A serration이 관찰되어 미세조직별로 serration type 의 차이가 나타났으나 차이의 원인을 알 수는 없었다.

합금조성 및 미세조직별로 최대인장강도의 차이가 동적 변형시효 발생 온도 구간에서 관찰되었다. 합금조성별로 보 면 그림 7(a)에서와 같이 상온에서는 $\mathrm{Cr}, \mathrm{Mo}$ 함량이 많은 P22 강이 모든 미세조직에서 최대인장강도가 높았으나 동 적 변형시효 온도구간에서는 ferrite-pearlite 조직의 $\mathrm{P} 11 \mathrm{AC}$ 에서 최대인장강도가 더 커지는 현상이 관찰되었다.
이는 앞서 설명한 바와 같이 그림 $1(\mathrm{a}),(\mathrm{b})$ 의 $\mathrm{Cr}, \mathrm{Mo}$ 함 량 차이에 의해 $\mathrm{P} 11$ 에 더 많은 용존 $\mathrm{C}$ 와 ferrite가 온도 증가에 따라 전위와 상호작용을 많이 하여 최대인장강도를 증가시킨 것으로 판단된다.

미세조직별로는 그림 5(a) P11에서 bainite 조직의 최대 peak가 ferrite-pearlite 조직보다 높은 값을 가지나 상대적 으로 저온에서 발생하였고 $\mathrm{P} 22$ 에서의 온도 별 최대인장강 도 변화를 나타낸 그림 6(a)에서도 bainite 조직의 최대 peak가 저온에서 발생한 것이 관찰되었다. 이는 Baird $[22,23]$ 등이 제시한 bainite에서 전위와 $\mathrm{Cr}-\mathrm{C}$ 에 의한 $\mathrm{ISSH}$ (Interaction Solid Solution Hardening) 효과와 ferrite에서 
전위와 $\mathrm{Mo}-\mathrm{C}$ 에 의한 ISSH 효과에 의한 현상과 일치하여 ISSH 효과와 관련 있는 것으로 생각된다.

그림 11에서의 serration 발생 온도와 그림 6(a)의 최대 인장강도의 최고 값 온도를 비교하였을 때 일부 변형률 속 도에서 최대인장강도값이 높게 나타나는 온도에서 serration 이 발생하지 않았다. 이는 HAYES [2]의 고온에서 탄화물 에 의한 침입형원소가 고갈되어 serration이 관찰되지 않는 다는 이론과 Mulford [24,25] 등의 고온에서 주변 전위에 의한 전위의 고착 등에 의해 serration이 관찰되지 않는 설 명으로 생각해 볼 수 있다.

$\mathrm{P} 11 \mathrm{AC}$ 의 활성화에너지값은 ferrite 강의 값들과 유사하 였다. $\mathrm{P} 22 \mathrm{AC}$ 의 값이 크게 측정된 것은 $\mathrm{Cr}, \mathrm{Mo}$ 에 의한 적은 용존 $\mathrm{C}$ 로 고온에서 치환형원소에 의한 ISSH 효과로 동적 변형시효가 발생하였기 때문으로 생각된다. $2.25 \mathrm{Cr}-$ $1 \mathrm{Mo}$ 강의 모재, 용접부, 열영향부에 대해 활성화에너지를 계산한 Laha [3]의 연구결과에서도 bainite 조직 모재의 활성화에너값은 $96 \mathrm{~kJ} / \mathrm{mol}$ 이고 용접부는 $180 \mathrm{~kJ} / \mathrm{mol}$, 열영 향부는 $208 \mathrm{~kJ} / \mathrm{mol}$ 로 계산되어 열영향부에서 활성화에너지 값이 큰 이유를 치환형원소에 의한 ISSH 효과로 설명하고 있다.

주증기배관 온도 $286^{\circ} \mathrm{C}$ 에서 파단전누설 개념을 적용하 기 위한 우수한 재료는 최대인장강도 값이 크고 파단연신 율도 상대적으로 좋은 bainite 조직의 $1.25 \mathrm{Cr}-0.5 \mathrm{Mo}$ 강으 로 판단된다.

\section{4. 결 론}

본 연구에서는 주증기배관 후보 재료 $1.25 \mathrm{Cr}-0.5 \mathrm{Mo}$ (ASME SA335 Gr.P11)와 2.25Cr-1Mo (ASME SA335 Gr.P22) 강에 대해 공냉과 오일냉각 열처리를 수행한 4종 의 시편으로 다양한 온도 및 변형률 속도 구간에서 인장 특성 및 미세조직 분석을 수행하여 합금원소 및 미세조직 차이가 동적 변형시효 특성에 미치는 영향을 평가하였다.

- Ferrite-pearlite 조직에서 $\mathrm{Cr}, \mathrm{Mo}, \mathrm{Si}$ 합금원소의 영향에 의해 열처리 후 용존 $\mathrm{C}$ 와 ferrite 조직이 많은 $1.25 \mathrm{Cr}-0.5 \mathrm{Mo}$ (P11AC)강이 2.25Cr-1Mo (P22AC)강 보다 저온부터 넓은 온도범위에서 serration이 발생하였고 동적 변형시효가 발 생하는 온도에서 더 큰 최대인장강도가 나타났다.

- 미세조직의 차이로 인해 $1.25 \mathrm{Cr}-0.5 \mathrm{Mo}(\mathrm{P} 11)$ 강의 ferrite-pearlite 조직과 bainite 조직의 serration의 시작온도, 온도 범위, type에서 차이를 보였으며, ISSH 효과에 의해 두 강 모두 bainite 조직 보다 ferrite-pearlite 조직의 최대 인장강도 최고점이 고온에서 나타났다.
- $1.25 \mathrm{Cr}-0.5 \mathrm{Mo}$ (P11)강의 활성화에너지 값은 94 103 kJ/ $\mathrm{mol}$ 으로 침입형원소에 의한 전위이동 억제로 동적 변형시효 가 발생하는 ferrite 강들의 값과 유사하였고, $\mathrm{Cr}, \mathrm{Mo}$ 함량 이 많은 $2.25 \mathrm{Cr}-1 \mathrm{Mo}$ 강의 활성화에너지값은 치환형원소에 의한 ISSH 효과로 $233 \mathrm{~kJ} / \mathrm{mol}$ 로 계산되었다.

\section{REFERENCES}

1. Westinghouse AP1000 Design Control Document Rev. 19, Appendix 3B, Leak-Before-Break Evaluation of the AP1000 Piping, 43 (2011).

2. R. W. HAYES and W. C. HAYES, Acta Metall. 32, 259 (1984).

3. K. LAHA, K. S. CHANDRAVATI, K. BHANU SANKARA RAO, and S. L. MANNAN, Z. Metallkd. 12, 839 (1994).

4. R. L. KLUEH, J. Nucl. Mater. 68, 294 (1977).

5. R. L. KLUEH and J. M. VITEK, J. Nucl. Mater. 126, 9 (1984).

6. R. L. KLUEH and R. W. SWINDEMAN, Metall. Trans. A, 17A, 1027 (1986).

7. B. K. Choudhary, K. Bhanu Sankara Rao, S. L. Mannan, and B. P. Kashyap, Mater. Sci. Technol. 15, 791 (1999).

8. C. GUPTA, J.K. CHAKRAVARTTY, and S. BANERJEE, Metall. Trans. A, 41A, 3326 (2010).

9. Preeti Verma, G. SudhakarRao, P. Chellapandi, G.S. Mahobia, Kausik Chattopadhyay, N.C. Shanthi Srinivas, Vakil Singh, Mater. Sci. Eng. A, 621, 39 (2015).

10. Juliermes. CP, Vitor LS,Ayrton SB, Luis PMS, Renata B, and Jose FRS, Int J Metall Met Phys, 4:40 (2019).

11. P. Rodriguez, Bull. Mater. Sci, 6, 653 (1984).

12. J. M. Robinson and M. P. Shaw, Int. Mater. Reviews, 39, No.3, 113 (1994).

13. P. G. McCORMICK, Acta Metall. 12, 197 (1978).

14. Van den Beukel, A, Acta Metall. 28, 965 (1980).

15. A. H. Cottrell, Dislocations and plastic flow in crystals, Oxford University press, London (1953).

16. V. Ollilainen. W. Kasprzak, and L. Holappa, J. Mat. Pro. Tech. 134, 405 (2003).

17. R.R.U. Queiroz, F.G.G. Cunha, and B.M. Gonzalez, Mater. Sci. Eng. A, 543, 84 (2012).

18. V.T.L. BUONO, M.S. ANDRADE, and B.M. GONZALEZ, Metall. Trans. A, 29A, 1415 (1998).

19. Berenice Mendonca GONZALEZ, Leandro Aparecido MARCHI, Evilmar Jose da FONSECA, Paulo Jose MODENESI, and Vicente Tadeu Lopes BUONO, ISIJ. Inter. 
43, 428 (2003).

20. R. L. KLUEH, Mater. Sci. Eng. 35, 239, (1978).

21. S.A. Nalawade, M. Sundararaman, R. Kishore, and J.G. Shah, Scr. Mater. 59, 991 (2008).

22. J.D. Baird and A. Jamieson, J. Iron Steel Inst. London. 21, 841 (1972).

23. Wendell B. Jones and J. A. Van den avyle, Metal. Trans. A 11A, 1275 (1980).

24. R. A. Mulford and U. F. Kochs, Acta Metall. 27, 1125 (1979).

25. K. G. Samuel, S. L. Mannan, and P. Rodriguez, Acta.
Metall. Mater. 40, 569 (1992).

26. B. J. Brindley and P. J. Worthington, Acta Metall. 17, 1357 (1969).

27. E. Pink, Acta Metall. 37, 1773 (1989).

28. X. Y. Fang, D. Q. Yi, and J. F. Nie, Metall. Mater. Trans. A40, 2761 (2009).

29. W. H. Wang, D. Wu, S. S. A. Shah, R. S. Chen, and C. S. Lou, Mater. Sci. Eng. A, 649, 214 (2016).

30. C. Marsh and D. Kaoumi, Mater. Sci. Eng. A, 707, 136 (2017). 